\title{
A role for Fibroblast Growth Factor Receptor 1 in the pathogenesis of Neisseria meningitidis
}

\author{
Sheyda Azimi ${ }^{a}$, Lee M. Wheldon, Neil J. Oldfield, Dlawer A. A. Ala'Aldeen ${ }^{\mathrm{b}}$ \\ and Karl G. Wooldridge*
}

Molecular Bacteriology and Immunology Group, School of Life Sciences, University of Nottingham.

apresent affiliation: Georgia Institute of Technology, Atlanta, Georgia, USA

bPresent affiliation: Middle East Research Institute, Dream City, Erbil, Kurdistan Region of Iraq

*corresponding author

Mailing address:

School of Life Sciences, Life Sciences Building, University of Nottingham, University Park, Nottingham, NG7 2RD, UK.

Email: karl.wooldridge@nottingham.ac.uk

Running title: FGFR1 and meningococcal pathogenesis

Declarations of interest: none

Keywords: Neisseria meningitidis, FGFR1, endothelial, host-pathogen 


\section{Abstract}

2 Neisseria meningitidis (the meningococcus) remains an important cause of human disease,

3 including meningitis and sepsis. Adaptation to the host environment includes many interactions

4 with specific cell surface receptors, resulting in intracellular signalling and cytoskeletal 5 rearrangements that contribute to pathogenesis. Here, we assessed the interactions between 6 meningococci and Fibroblast Growth Factor Receptor 1-IIIc (FGFR1-IIIc): a receptor specific to 7 endothelial cells of the microvasculature, including that of the blood-brain barrier. We show 8 that the meningococcus recruits FGFR1-IIIc onto the surface of human blood microvascular 9 endothelial cells (HBMECs). Furthermore, we demonstrate that expression of FGFR1-IIIc is 10 required for optimal invasion of HBMECs by meningococci. We show that the ability of

$11 N$. meningitidis to interact with the ligand-binding domain of FGFR1-IIIc is shared with the 12 other pathogenic Neisseria species, N. gonorrhoeae, but not with commensal bacteria including 13 non-pathogenic Neisseria species. 


\section{Introduction}

16 Neisseria meningitidis, or the meningococcus, while normally a harmless commensal of the human oropharynx, can occasionally cause devastating disease including meningitis, sepsis, oropharyngeal epithelial mucosa and entry into the bloodstream by meningococci is a crucial step in development of systemic disease, while penetration of the blood-brain barrier (BBB) is a prerequisite for development of meningitis $[2,3]$. Attachment to vascular endothelial cells induces membrane protrusions at meningococcal binding site and leads to formation of specific protein complexes known as cortical plaques underneath meningococcal colonies [4-7]. The process by which these steps occur is not fully understood [8-12]. Adhesion to human cells by meningococci is mediated by the type IV pilus, major adhesins including Opa and Opc [13, 14], as well as a number of additional adhesins including the porins PorA [15] and PorB [16], and sialic acid residues on either lipooligosaccharide or the Group B polysaccharide capsule [17]. While a number of host cell receptors interacting with meningococci including alpha actinin $[18]$, integrins $[8,19,20]$, carcinoembryonic antigen-related cell adhesion molecules (CEACAMs) [21, 22], CD46 [23, 24], platelet activating factor receptor [25], laminin receptor $[15]$, galectin-3 [26], and receptor tyrosine kinases $[27,28]$, have been identified, no tissuespecific receptors for this pathogen have been identified.

Fibroblast Growth Factor Receptors (FGFRs) are transmembrane proteins that belong to the Receptor Tyrosine Kinase (RTK) family of signalling molecules [29]. Four members comprise the family and are responsible for recognising the 22 Fibroblast Growth Factors (FGFs) found in humans [30-32]. FGFs are involved in cell differentiation, migration and proliferation during early embryogenesis and play an important role in tissue repair, wound healing [33] and tumour angiogenesis in adulthood [29, 34, 35]. Splicing of FGFR transcripts generates a variety of specific isoforms in different cell types and tissues, recognising specific types of FGF molecules [29, 31, 36, 37].

FGFRs are single transmembrane receptors; the extracellular $\mathrm{N}$-terminal region consists of three IgG-like domains that form a ligand-binding domain with an acidic box which interacts with heparin sulphate proteoglycans (HSPGs) and cell adhesion molecules (CAMs) [38]. This is followed by a transmembrane region and a C-terminal cytoplasmic region containing 7 specific tyrosine residues [39-42]. Binding of FGFs to the receptors leads to dimerization of the receptor and tyrosine autophosphorylation, which in turn activates the receptor, triggering downstream signalling pathways [43-46]. FGFR1 signalling and expression is important in maintaining the integrity and differentiation of endothelial cells forming the microvasculature [34, 47, 48]. Here, we demonstrate specific interaction of FGFRs in human brain microvascular endothelial cells (HBMECs) with meningococci, and show that this interaction influences the ability of $N$. meningitidis to invade these cells. 


\section{Materials and methods}

\subsection{Bacterial growth and culture}

E. coli JM109 cells (Promega) were grown on Lysogeny Broth agar (Oxoid) supplemented where appropriate with $100 \mu \mathrm{g} / \mathrm{ml}$ ampicillin (Sigma). N. meningitidis serogroup B strain MC58 (ATCC $®$ BAA335 ${ }^{\mathrm{TM}}$ ) [49] and clinical isolates of $N$. meningitidis from our laboratory collection, N. gonorrhoeae strain FA1090 (ATCC 700825), N. lactamica strain ATCC23970, N. polysaccharea (a clinical isolate from laboratory stocks), H. influenzae Rd KW20 (ATCC 51097) [50], and S. pneumoniae T4 (unencapsulated) [51] were routinely cultured on chocolated horse blood agar (Chocolate agar, Oxoid) at $37^{\circ} \mathrm{C}$, in an atmosphere of air plus $5 \% \mathrm{CO}_{2}$.

\subsection{Cell association assay and cell invasion (Gentamicin protection) assay}

To quantify cell association and cell invasion of HBMECs with $N$. meningitidis HBMECs were seeded and grown overnight or for $48 \mathrm{~h}$ after siRNA transfection until $100 \%$ confluent in 24 well plates. Cells were infected with $1 \times 10^{7} \mathrm{CFU}$ bacteria for $4 \mathrm{~h}$ in ECM-b media without any supplements. Cell association and invasion were then determined as described previously [52].

\subsection{Confocal Immunofluorescent Microscopy}

HBMECs were seeded onto fibronectin-coated coverslips (ca. $1 \times 10^{5}$ cells) and grown overnight to reach a confluency of $70-80 \%$. Cells were infected for 4 h (MOI 200). Coverslips were washed with PBS and fixed with 4\% paraformaldehyde (w/v) in PBS for $5 \mathrm{~min}$. Coverslips were then washed with PBS and blocked in $4 \%(\mathrm{w} / \mathrm{v}) \mathrm{BSA} / \mathrm{PBS}$ at $4^{\circ} \mathrm{C}$ overnight. For intracellular staining, cells were permeabilised using $0.1 \%$ Saponin, $20 \mathrm{mM}$ glycine in $4 \% \mathrm{BSA} / \mathrm{TBS}$ at $4^{\circ} \mathrm{C}$. Subsequent staining procedures were carried out in $4 \%(w / v)$ BSA/TBS. Briefly, coverslips incubated with primary antibody for $1 \mathrm{~h}$ were washed with PBS followed by one wash with $\mathrm{dH}_{2} \mathrm{O}$. Coverslips were then incubated with secondary antibody for $1 \mathrm{~h}$ in the dark followed by washes with PBS-Tween $(0.05 \% \mathrm{v} / \mathrm{v} ; \mathrm{PBS}-\mathrm{T})$, PBS and then $\mathrm{dH}_{2} \mathrm{O}$. Coverslips were then mounted on glass slides with ProLong $\AA$ Gold and SlowFade $\AA$ Gold Antifade Reagents with DAPI (Invitrogen). Coverslips were analysed using a Zeiss LSM-700 confocal microscope. Images were processed with Image], Adobe Photoshop and LSM Image Browser software.

\subsection{Antibodies and reagents}

Antibodies detecting FGFR1: Flg S-16 (goat polyclonal antibody) and Flg C-15 (mouse antibody), phosphorylated FGFR1 (p-Y766, mouse monoclonal antibody), Alpha-actinin (sc-17829) and Rab5 (sc-46692) were purchased from Santa Cruz Biotechnology. Secondary antibodies conjugated to various fluorochromes, and Phalloidin conjugated to fluorochrome 488 were obtained from Life Technologies-Invitrogen. The antibody detecting 37LRP (A-7) was 
purchased from Santa Cruz Biotechnology and antibody against 67LR (Mluc-5) was purchased from Thermo Scientific.

\subsection{Cloning and expression of FGFR1 IIIC and FC-stop}

HBMECs grown in fibronectin-coated T75 flasks (BD Bioscience) were harvested by trypsin treatment and centrifugation for $5 \mathrm{~min}$ at $300 \times \mathrm{g}$. Cells were lysed in lysis buffer (SIGMA GenElute $^{\mathrm{TM}}$ Mammalian Total RNA Miniprep Kits) supplemented with $1 \%$ (v/v) 2- $\beta$ Mercaptoethanol and RNA was extracted according to the manufacturer's protocol (Sigma GenElute $^{\mathrm{TM}}$ Mammalian Total RNA Miniprep Kit). The concentration of RNA was measured using a Nanodrop spectrophotometer and adjusted to $200 \mathrm{ng} \mathrm{\mu l}^{-1}$. DNase treatment was performed following the manufacturers protocol (Turbo DNase, Life Technologies). $10 \mu$ of RNA was used for cDNA preparation using the High Capacity cDNA Reverse Transcription kit (Applied Biosystems). HBMEC cDNA was then used as template to amplify the extracellular domain of FGFR1 IIIc isoform using primers designed to amplify the extracellular domain of FGFR1 and containing restriction sites for restriction enzymes NdeI (Forward; GCGGCTTAATCATATGCAGGGACCCGGATCCATGTGGAGCTGGAAGTGCC) and NotI (Reverse; GCGCGATTAAGCGGCCGCttaCAGGGGCGAGGTCA). The amplified PCR product was gel purified, digested and then ligated into NotI and NdeI-digested pEF-Bos-ss-Fc-FGFR2IIIaTM-ires-TPZ [53-55] using the LigaFast TMRapid DNA Ligation System (Promega). The ligated plasmid was used for transformation of competent E. coli JM109 cells (Promega). The resulting plasmid was named pEF-Bos-ss-Fc-extFGFR1IIIc-ires-TPZ. A plasmid expressing LAMR1, which has been described previously [56], was mutated to introduce a stop codon at the junction of the sequence encoding FC and LAMR1, resulting in a plasmid designated pEF-Bos-Ss-Fc-Stop-LRPires-TPZ encoding the Fc tag (Fc-stop) only. For expression of Fc-tagged FGFR2 IIIa TM, pEFBos-ss-Fc-extFGFR1IIIc-ires-TPZ and Fc-tag, 293T cells were grown overnight to 30\% confluence in Dulbecco's Modified Eagle Medium (DMEM; Gibco) supplemented with FCS $(10 \% \mathrm{v} / \mathrm{v})$ and transfected by calcium phosphate precipitation. Media was collected $72 \mathrm{~h}$ posttransfection and Fc-tagged recombinant proteins were purified on a Protein AIG-Sepharose (Source BioScience LifeSciences) column. Protein concentration in each fraction was quantified using the BCA kit following manufacturer's protocol (Thermo Scientific).

\subsection{FGFR1 siRNA transfection in HBMECs}

Human FGFR1 SiRNA (siGENOME SMART pool) and control scrambled siRNA were obtained from Dharmachon/Thermo Scientific and reconstituted following the manufacturer guidance. FGFR1 SiRNA was resuspended in $1 \mathrm{ml}$ of $1 \times$ siRNA buffer to a final concentration of $50 \mu \mathrm{M}$ (stock). HBMECs were seeded into 24-well plates pre-coated with fibronectin, as previously described, and grown overnight to reach a confluency of $70-80 \%$. Transfection media was prepared by mixing serum- and antibiotic-free media with siRNA from a $50 \mu \mathrm{M}$ stock to a final concentration 
of $5 \mu \mathrm{M}$; in a separate tube Transfection reagent number 1 (Thermo Scientific-Dharmacon) was added to serum and antibiotic-free media. Both tubes were incubated for 5 min at room temperature and then mixed together by pipetting and incubated at room temperature for 20$30 \mathrm{~min}$. Cells were washed with serum and antibiotic-free medium and $240 \mu \mathrm{l}$ of complete media without antibiotics were added to each well and then the transfection mixture was added drop-wise to each well to a final concentration of $50 \mathrm{nM}$ siRNA/ well. Cells were then incubated for $6 \mathrm{~h}$ and then the media was replaced with complete media (Endothelial cell medium (ECMb) (ScienCell) supplemented with ECGS (containing EGF, VEGF) (ScienCell) (1\% v/v) and FBS ( $5 \% \mathrm{v} / \mathrm{v}$ ) and penicillin/streptomycin (ScienCell; 1\% v/v). The level of FGFR1 expression was examined at RNA and protein levels at 24,48 and $72 \mathrm{~h}$ post transfection.

\subsection{ELISA}

96-well plates (NUNC Immobilizer Amino) were coated with $100 \mu \mathrm{l}$ of protein A (Pierce; $1 \mu \mathrm{g}$ $\mathrm{ml}^{-1}$ ) in PBS for $1 \mathrm{~h}$, washed once with PBS-T and then $86.5 \times 10^{-15} \mathrm{M}$ of Fc-tagged recombinant proteins added to each well in carbonate buffer $(\mathrm{pH} 9.6)$. Plates were incubated for $1 \mathrm{~h}$ and then washed three times with PBS-T. Plates were blocked with $1 \%$ BSA/PBS (w/v) for $1 \mathrm{~h}$, then washed once with PBS-T. Bacterial cells harvested from overnight plates and resuspended in PBS-T, washed with the same buffer three times and finally resuspended in sodium carbonate buffer (44 mM NaHCO $3,6.0 \mathrm{mM} \mathrm{Na} \mathrm{CO}_{3} ; \mathrm{pH}$ : 9.6). The $\mathrm{OD}_{600}$ was measured and $20 \mathrm{ng}(2 \mu \mathrm{l}$ of $10 \mathrm{ng} \mathrm{ll}^{-1}$ ) of digoxigenin (DIG; Roche) was added to $1 \mathrm{ml}$ of bacterial suspension with $\mathrm{OD}_{600}: 1$. The bacterial suspensions were incubated for $2 \mathrm{~h}$ in the dark at room temperature on the shaker. Bacteria then were washed three times with PBS-T by centrifugation $(13000 \times g$ for 1 minute) and resuspended in $1 \%$ BSA/PBS (w/v). OD 600 in $1 \%$ BSA/PBS was adjusted to 0.02 for ELISA. For each experiment freshly labelled bacterial strains were used. $100 \mu$ of DIGlabelled bacteria were added to each well and plates were incubated at $4^{\circ} \mathrm{C}$ overnight then washed five times with PBS-T. $100 \mu \mathrm{l}$ of anti-DIG-alkaline phosphatase antibody (Roche; $0.0002 \mathrm{v} / \mathrm{v}$ ) in $1 \%$ BSA/PBS was then added to each well and incubated for $1 \mathrm{~h}$ then washed three times with PBS-T. $200 \mu \mathrm{l}$ of alkaline phosphatase substrate (SIGMA) was added and plates were incubated for $1 \mathrm{~h}$. The $\mathrm{OD}_{405}$ was measured for each sample and values obtained subtracted from the binding of the same DIG-labelled strain to $1 \%$ BSA/PBS. 


\subsection{N. meningitidis colonies recruit FGFR1 on the apical surface of Human Brain Microvascular Endothelial Cells (HBMECs).}

To study the possible interaction of FGFR1 by meningococcal colonies, HBMECs were infected with $N$. meningitidis for $4 \mathrm{~h}$, fixed, and prepared for subsequent investigation by immunofluorescence microscopy. FGFR1 was recruited by meningococcal colonies on the apical surface of HBMECs (Figure 1-A). Previously, we have shown that meningococci interact with both the $67-\mathrm{kDa}$ laminin receptor (67LR) and the 37-kDa laminin receptor precursor (37LRP) isoforms of the laminin receptor $[15,56]$. Here, we show that FGFR1 recruitment to meningococcal colonies coincided with recruitment of both isoforms of this receptor (Figure 1A). To address whether FGFR1 recruited by meningococci is activated, HBMECs were labelled with primary antibodies specific for phosphorylated tyrosine 766 ( $p$-Y766), which is a feature of the activated form of FGFR1, and with antibodies specific for the two main isoforms of the laminin receptor, 67LR and 37LRP. In all cases the phosphorylated FGFR1 co-localised with meningococcal cells (Figure 1-B). Meningococcal colonies co-localised with FGFR1 and 37LRP, up to $60 \%$ of which co-localised with FGFR1. This was significantly higher than co-localisation of the microcolonies with the 67LR isoform of the laminin receptor (Figure 1-C).

\subsection{Internalized $\boldsymbol{N}$. meningitidis associated with activated FGFR1.}

To determine whether internalised bacteria were associated with activated FGFR1, HBMECs were infected for $4 \mathrm{~h}$ with $N$. meningitidis and non-internalised bacterial cells were killed by treatment with gentamicin. Immunofluorescent staining for actin (phaloidin) and activated FGFR1 ( $p$-Y766) confirmed that meningococci recruited activated FGFR1 in the cytoplasm of HBMECs, and that the receptor was trafficked inside the cells alongside with meningococcal cells (Figure 2). To confirm that the bacterial cells in gentamycin-treated monolayers were internalised, a Z-stack image was constructed. Bacterial cells could be observed beneath the membrane of the endothelial cells (Figure 2-B and 2C). To determine whether the internalised bacteria were associated with endosomes we probed infected monolayers for Rab5. Internalised bacteria associated with activated FGFR1 were also co-located with this marker for early endosomes, indicating that the bacteria were endosome-associated (Figure 2D).

\subsection{FGFR1 expression is required for meningococcal invasion into HBMECs.}

To determine whether interaction of meningococci with FGFR 1 on the surface of HBMECs was required for internalisation of the bacteria, FGFR 1 expression was knocked down in HBMECs using siRNA treatment. Sixty hours post-siRNA treatment, cells were infected with meningococci and cell association and invasion assays were performed. The numbers of meningococcal cells associated with HBMECs was significantly and dramatically reduced in 
response to FGFR1 knock-down (Figure 3-A). Treatment with scrambled siRNA under the same conditions did not result in a significant reduction in association of meningococci with HBMEC cells. There was also a significant decrease in the number of internalised meningococcal cells recovered from FGFR1 siRNA-transfected HBMECs (Figure 3-B). Again, treatment with a scrambled siRNA did not significantly affect binding of meningococci to the HBMEC cells. This demonstrates that FGFR 1 expression plays an important and specific role in meningococcal adhesion to and invasion into HBMECs.

\subsection{N. meningitidis interacts specifically with FGFR1 IIIc.}

To determine which isoforms of FGFR1 are expressed in HBMEC cells we performed RT-PCR using cDNA generated from total RNA extracted from HBMECs. Various combinations of primers specific for exon 7, 8 and 9 for FGFR1, FGFR2 and FGFR3 were used to determine which isoforms of FGFR were expressed. Amplification products across exons 7 and 9 of FGFR1, corresponding to FGFR1 IIIc, but not across exons 7 and 8, corresponding to FGFR1 IIIb were detected, while amplification across exons 7 and 8, corresponding to FGFR3 IIIb, but not across exons 7 and 9, corresponding to FGFR3 IIIc were amplified. No amplicons were detected across either exons 7 and 8 or exons 7 and 9 of FGFR2. Thus, FGFR1 IIIc and FGFR3 IIIb isoforms were both expressed in HBMECs. To determine whether meningococci could interact directly with the extracellular domain of FGFR1 IIIc this protein was cloned and expressed as an Fctagged fusion protein. Two other proteins: Fc-FGFR2 IIIa TM, comprising the trans-membrane region of FGFR2 IIIa fused to the immunoglobulin Fc domain, and the Fc portion of immunoglobulin alone (Fc-stop) were used as controls for possible interaction with N. meningitidis that was not specific for the FGFR1 IIIc extracellular domain. Both control proteins were derived from clones employing the same vector and purified by the same method as Fc-FGFR1 IIIc. Each of the purified proteins were employed as an immobilised ligand in ELISA experiments to assess the ability of DIG-labelled $N$. meningitidis (MC58) to bind to these ligands. N. meningitidis (MC58) bound Fc-FGFR1 to a significantly greater degree than either FC-FGFR2 IIIa TM or Fc-stop (Figure 4 A). This indicates that the observed interaction of FcFGFR1 was not due to meningococci binding to the Fc-tag of the expressed extracellular domain of FGFR1 and thus demonstrates a direct interaction between the receptor present on the apical surface of HBMECs and surface structures of $N$. meningitidis.

\subsection{Interaction between $N$. meningitidis and FGFR1 is common among clinical} isolates of different serogroups and is shared by $\mathbf{N}$. gonorrhoeae but not commensal Neisseria species, nor other bacterial pathogens targeting the meninges.

Having shown that FC-FGFR1 IIIc interacts with meningococci, we sought to establish whether other Neisseria species could interact with this receptor. We tested representative strains belonging to several Neisseria species, including the human pathogen $N$. gonorrhoeae and the normally non-pathogenic species $N$. polysaccharea and $N$. lactamica, for interaction with Fc- 
223 FGFR1 in ELISA assays. N. gonorrhoeae cells bound to wells containing FC-FGFR1 at similar 224 levels to $N$. meningitidis MC58, and to a significantly higher level than to FGFR2. In both cases $225 \quad$ N. gonorrhoeae bound to Fc-FGFR1 to a significantly higher degree than either of the two 226 commensal species, which did not bind to a significantly higher degree to Fc-FGFR1 than to 227 control wells containing only Fc-FGFR2 TM (Figure 4 B). To determine whether binding of 228 N. meningitidis to FGFR1 was a phenomenon common to other isolates of $N$. meningitidis we 229 tested a panel of $N$. meningitidis isolates belonging to serogroups $A, B, C$ and $X$. All strains 230 were able to bind Fc-FGFR1 specifically at levels similar to the serogroup B strain MC58 (Figure 2314 C). We previously showed that, like the meningococcus, the pathogens S. pneumoniae and $232 H$. influenzae, both of which are known to target the meninges, each targeted the laminin 233 receptor on HBMEC cells as a prerequisite for internalisation [15]. Neither representative $S$. 234 pneumoniae nor $H$. influenzae strains bound significantly to Fc-FGFR1 (Figure 4 D), 235 demonstrating that the observed interaction between the pathogenic Neisseria species was 236 specific. 
The interactions between meningococci and the BBB are central to the ability of this pathogen to cause meningitis, but they are complex and incompletely understood. Meningococci have been shown to interact with brain microvascular endothelial cells (BMECs) through various molecules of both the bacterium and the endothelial cell and several of these interactions result in disruption of the BBB and favour bacterial entry into the cerebro-spinal fluid. Type IV pili, for example, initiate initial binding to human brain endothelial cells via the pilin molecules PilQ, PilE and PilV, which bind to host laminin receptor [15], CD147 and $\beta$-adrenergic receptor [57], respectively. The latter receptor acts as a mechano-sensor, signalling via the $\beta 2$ adrenoceptor/ $\beta$-arrestin pathway and recruits Src tyrosine kinase and junctional complex proteins to the site of bacterial attachment $[57,58]$. Pilus-mediated meningococcal attachment to BMECs results in recruitment of adherens junction complex components (VE-cadherin, p120catenin, $\beta$-catenin), tight junction components (ZO1, ZO2 and caludin-5), and the Par3/Par6/PKCz polarity complex to the site of bacterial attachment. This results in disruption of adherens junctions and tight junctions and the opening of the paracellular pathway [59]. Meningococci also interact with BMECs indirectly via the major adhesin Opc, which binds fibronectin and thus allows the bacterium to interact with the integrin a-5 $\beta$-1-receptor on the endothelial cell surface [60]. Opc/integrin-mediated interaction of endothelial cells with meningococci results in activation and phosphorylation of JNK1 and JNK2, as well as their substrates C-Jun, resulting JNK1 and JNK2-dependent invasion [8]. Meningococci also activate p38 MAPK, but this interaction is independent of the Opc/integrin interaction, and results in the induction of the inflammatory cytokines IL-6 and IL-8 [8]. Attachment of meningococci to endothelial cells also initiates secretion of host matrix metalloproteinase-8, which results in cleavage of the tight junction component occludin, which in turn leads to increased paracellular permeability [61].

A number of receptor tyrosine kinases have been shown to be important for the interaction between BMECs and meningococci. Several activated RTKs including the EebB family receptors epidermal growth factor receptor (EGFR), ErbB2 and ErbB4 were shown to be activated in endothelial cells after interaction with meningococci [27]. A requirement for Focal Adhesion Kinases and activation of Src in the internalization of meningococci via interaction with integrins has also been demonstrated [20]. Considering the role of FGFR1 in maintaining the integrity of the BBB and angiogenesis [62], we examined the possible role of FGFR1 in interactions with meningococci. HBMECs infected with meningococci were shown to recruit FGFR1 to their apical surface. Recently, we showed that meningococci bind to both 37LRP and Galectin-3 on the surface of HBMECs [56]. Here, we showed that FGFR1 recruitment coincided with recruitment of both isoforms (37LRP and 67LR) of the laminin receptor; molecules already implicated in N. meningitidis-HBMEC interactions [15]. Ligation of the extracellular domain of FGFRs by their 
ligands leads to auto-phosphorylation of tyrosine residues in the cytoplasmic domain of the receptor; these phosphorylated residues subsequently serve as docking sites for a number of adaptor proteins responsible for regulation of various downstream signalling cascades [31]. The FGFR1 molecules recruited by meningococci were shown to be activated and activated receptors and meningococcal cells also co-localised with a-actinin. The microcolonies were also associated with the early endosomal marker Rab5, confirming that the bacteria were entering the endosomal pathway. This is in agreement with previous studies on the trafficking of FGFR1 into early endosomes inside the cytoplasm, and the regulation of its trafficking by Syndecan 4 in a clathrin-independent manner [63]. We also demonstrated by confocal microscopy in HBMECs treated with gentamicin that the receptor is internalised into the cytoplasm along with invading meningococci. To determine whether FGFR1 was required for meningococcal-HBMECs interactions, FGFR1 expression was transiently inhibited by using FGFR1 siRNA transfection. FGFR1 knock-down in HBMECs resulted in a dramatic reduction in both association and internalisation of meningococci into HBMECs. Surprisingly, the residual levels of both cellular association and invasion were very low as we would have expected there to be interaction via the other known receptors for the pathogen. Our data confirm that direct interaction between the extracellular domain of FGFR1 and meningococci is required for consequent activation of the receptor and internalisation of bacteria into the HBMECs.

The mechanisms by which recruitment of FGFR1 by meningococcal colonies leads to their internalisation is unknown. Interaction of meningococci with HBMECs has previously been shown to lead to higher levels of activation of ERK 1, 2 due to activation of ErbB2 in these cells [28]. However, levels of ERK 1,2 activation in cells in which FGFR1 was knocked down by siRNA transfection were unaffected, demonstrating that FGFR1 does not regulate the levels of ERK1, 2 activation [64]. Several studies on meningococcal infection of endothelial cells showed that invasion of bacteria requires activation of Src, phosphorylation of cortactin via the Src pathway and activation of focal adhesion kinases (FAKs) $[20,28,65]$. Also, it has been shown that meningococcal cells hijack the $\beta$-arrestin/ $\beta$ 2-adrenoreceptor pathway to invade endothelial cells and cross the BBB: inhibition of $\beta$-arrestin mediated activation of Src, prevents the invasion of meningococcal cells [58]. Src is required for cortactin phosphorylation by FGF1 which can provide an alternate downstream pathway of FGFR1 from PLCY and can be involved in cytoskeletal rearrangement $[66,67]$. However it was reported that mutation of $Y 766$ in FGFR1 leads to higher level activations of PLCY which inhibits Src activation [68]. These observations suggest that FGFR1 siRNA transfection of HBMECs may have led to the same effect on inhibition of Src activation which consequently inhibited meningococcal invasion into HBMECs. This effect appears to be specific to the meningococcus as the bacterial pathogens $H$. influenzae and $S$. pneumoniae, which also cross the BBB and can cause meningitis, do not interact with FGFR1 IIIc on the surface of HBMECs. On the other hand, N. gonorrhoeae, which 
311 does not usually interact with the BBB is also able to interact with FGFR1 IIIc to the same 312 extent as $N$. meningitidis.

313 Although the specific role of FGFRs in infectious diseases has not been excessively investigated, 314 an increase in FGF2 expression enhances Chlamydia trachomatis binding and internalisation 315 into epithelial cells [69]. C. trachomatis facilitates entry by binding directly to FGF2, which 316 results in binding of FGF2-bacteria-heperan sulfate proteoglycan (HSPG) complexes to FGFR and internalisation of the elementary bodies of these bacteria into the cells. More recently, HSPG-associated FGFR1 has been implicated in internalisation of Rickettsia rickettsii into cultured human microvascular endothelial cells and inhibition of FGFR1 in a $R$. conorii murine model of endothelial-target spotted fever rickettsiosis; reduced the rickettsial burden in infected mice [70].

322 Interaction of meningococci and FGFR1 in BMECs occurs within a complex network of interactions. The various pathways are likely to be both synergistic and antagonistic. FGFR1 engagement by basic fibroblast growth factor receptor has recently been shown to protect the integrity of HBMEC monolayers preventing the downregulation of the junction proteins $\mathrm{ZO}-1$, occludin and VE-cadherin in response to oxygen-glucose deprivation and deoxygenation [71]. This is in contrast to the known effects of meningococcal interactions on these molecules. Thus, engagement of FGFR1 may favour a trans-cellular pathway through HBMECs rather than a para-cellular pathway in which the integrity of the monolayer would have to be compromised. Further investigations are required to identify and unravel the role of FGFR1 signalling in meningococcal invasion into HBMECs and other type of endothelial cells forming the microvasculature in other organs. 


\section{Declaration of competing interest: none}

\section{Acknowledgements}

335 We thank Dr S. Morroll for constructing the plasmid encoding Fc-Stop-LRP and Professor Kim

336 (John Hopkins University School of Medicine, Baltimore, US) for providing HBMEC cells.

\section{Funding Statement}

338 This work was funded by the Medical Research Council, UK (www.mrc.ac.uk); award number

339 G0801173. The funders had no role in study design, data collection and analysis, decision to 340 publish, or preparation of the manuscript. 
Figure 1. Activated FGFR1 is recruited by meningococcal colonies. (A) HBMECs were infected with meningococcal cells (MOI: 200) for $4 \mathrm{~h}$. Neisseria meningitidis colonies were visualized with DAPI (blue), FGFR1 was probed with anti-FGFR1 primary antibody and detected with anti-goat Alexa Fluor 680 antibody (red). 37LRP and 67LR were probed with primary antibodies and detected with anti-mouse Alexa Fluor 488 antibodies (green). FGFR1 was recruited by meningococcal colonies, which coincides with recruitment of $37 \mathrm{LRP}$ and, to a less extent, 67LR. Co-localizations area is shown by arrows (images are representative of 10 infected cells). (B) FGFR1 phosphorylated at Tyrosine 766 ( $p$-Y766) was labelled with Alexa Fluor 680 (red) and both isoforms of Laminin receptor (67LR and 37LRP) with Alexa Fluor 488 (green). Recruitment of activated FGFR1 ( $p$-Y766) coincided with recruitment of 37LRP and, to a less extent, 67LR. (C) Levels of co-localization of MC58 with 37LRP, 67LR and p-Y766 (activated FGFR1) were quantified by measuring the percentage of co-localization of each receptor with MC58 in 30 fields. There was a significant difference between recruitment by MC58 of activated FGFR1 or 37LRP with recruitment of 67LR $(p=0.04$, One Way ANOVA, multiple comparison, Dunn's Test).

Figure 2. Activated FGFR1 is recruited by internalised meningococci within HBMECs. (A) In infected HBMECs a-actinin and actin were labelled with Alexa Fluor 680 (Red) and the activated form of FGFR1 labelled with Alexa Fluor 488 (Green). Bacteria were labelled with DAPI (Blue). Internalized bacteria co-localized with both a-actinin (sc-17829), actin (phaloidin) and activated FGFR1 ( $p$-Y766) (arrowheads). (B) Z-stack image of meningococcal colonies shows that internalized bacteria (co-localizing with a-actinin) recruit activated FGFR1 ( $p$-Y766) inside the cells. (C) Orthogonal view of Z-stack image of meningococcal colonies on the apical surface (arrows) of the cells which only recruited activated FGFR1 (p-Y766, Green) and internalized colonies colocalizing with in a-actinin (pY766). (D) Infected HBMECs probed for activated FGFR1 $(p-Y 766)$ and Rab5 (sc-46692) showing bacteria co-localised with both molecules.

Figure 3. FGFR1 down regulation plays an important role in invasion of meningococci into HBMECs. (A) HBMECs were infected with Nm MC58 for 4h (MOI: 10). Cells were washed and lysed in $500 \mu \mathrm{l}$ of $1 \%$ saponin in PBS and $100 \mu \mathrm{l}$ of homogenized lysates used for serial dilution preparation. $10 \mu \mathrm{l}$ of each dilution was plated onto chocolate agar and CFUs were calculated for each sample. There was a significant reduction in the number of meningococci associated with HMBECs after FGFR1 knockdown (FGFR1 siRNA; $p=0.0031$, two-tailed unpaired t-test, $n=8$ ). Experiments were performed in triplicate wells and means shown represent 8 independent experiments. (B) For invasion assays, gentamicin was added after $4 \mathrm{~h}$ of infection and plates were incubated for a further $1 \mathrm{~h}$. Cells were then washed, lysed, homogenised and dilutions plated onto chocolate blood agar plates. There was a significant difference between the number of internalised meningococci in untreated cells compared to HBMECs transfected with FGFR1 siRNA $(p=0.0003$, two-tailed t-test, $\mathrm{n}=7)$. Error bars represent standard deviation of mean. 

domain of FGFR1. Fc-tagged purified proteins were used as the immobilised ligand in ELISA experiments. Levels of interaction with DIG-labelled bacteria were measured; the values shown are those following subtraction of binding to $1 \%$ BSA/PBS. (A) N. meningitidis MC58 interacts directly with the extracellular domain of Fc-FGFR1 (two tailed t-test; each experiment was performed in 6 technical replicates and the data shown is derived from 6 independent experiments). (B) Binding of commensal Neisseria, but not N. gonorrhoeae, to FGFR1 IIIc was significantly lower than that shown by Nm MC58. (C) Clinical isolates of serogroups $A, B$ and $C$ of $N$. meningitidis, display similar binding levels to FGFR1 IIIC, when compared to MC58. (D) The meningeal pathogens $H$. influenzae and S. pneumoniae bound FGFR1 IIIc to a negligible degree that was significantly lower than cells of Nm MC58 $(p \leq 0.002)$. 
[1] Takada S, Fujiwara S, Inoue T, Kataoka Y, Hadano Y, Matsumoto K, et al. Meningococcemia in Adults: A Review of the Literature. Intern Med. 2016;55:567-72.

[2] Nassif $X$. Interaction mechanisms of encapsulated meningococci with eucaryotic cells: what does this tell us about the crossing of the blood-brain barrier by Neisseria meningitidis? Current opinion in microbiology. 1999;2:71-7.

[3] Virji M. Pathogenic neisseriae: surface modulation, pathogenesis and infection control. Nature reviews Microbiology. 2009;7:274-86.

[4] Merz AJ, Enns CA, So M. Type IV pili of pathogenic Neisseriae elicit cortical plaque formation in epithelial cells. Mol Microbiol. 1999;32:1316-32.

[5] Eugene E, Hoffmann I, Pujol C, Couraud PO, Bourdoulous S, Nassif X. Microvilli-like structures are associated with the internalization of virulent capsulated Neisseria meningitidis into vascular endothelial cells. J Cell Sci. 2002;115:1231-41.

[6] Stephens DS, Hoffman LH, McGee ZA. Interaction of Neisseria meningitidis with human nasopharyngeal mucosa: attachment and entry into columnar epithelial cells. J Infect Dis. 1983;148:369-76.

[7] Coureuil M, Bourdoulous S, Marullo S, Nassif X. Invasive meningococcal disease: a disease of the endothelial cells. Trends Mol Med. 2014;20:571-8.

[8] Sokolova O, Heppel N, Jagerhuber R, Kim KS, Frosch M, Eigenthaler M, et al. Interaction of Neisseria meningitidis with human brain microvascular endothelial cells: role of MAP- and tyrosine kinases in invasion and inflammatory cytokine release. Cell Microbiol. 2004;6:1153-66.

[9] Hill DJ, Griffiths NJ, Borodina E, Virji M. Cellular and molecular biology of Neisseria meningitidis colonization and invasive disease. Clin Sci (Lond). 2010;118:547-64.

[10] Yazdankhah SP, Caugant DA. Neisseria meningitidis: an overview of the carriage state. J Med Microbiol. 2004;53:821-32.

[11] Simonis A, Hebling S, Gulbins E, Schneider-Schaulies S, Schubert-Unkmeir A. Differential activation of acid sphingomyelinase and ceramide release determines invasiveness of Neisseria meningitidis into brain endothelial cells. PLoS Pathog. 2014;10:e1004160.

[12] Bernard SC, Simpson N, Join-Lambert O, Federici C, Laran-Chich MP, Maissa N, et al. Pathogenic Neisseria meningitidis utilizes CD147 for vascular colonization. Nat Med. 2014;20:725-31.

[13] Carbonnelle E, Hill DJ, Morand P, Griffiths NJ, Bourdoulous S, Murillo I, et al. Meningococcal interactions with the host. Vaccine. 2009;27 Suppl 2:B78-89.

[14] Merz AJ, So M. Interactions of pathogenic neisseriae with epithelial cell membranes. Annual review of cell and developmental biology. 2000;16:423-57.

[15] Orihuela CJ, Mahdavi J, Thornton J, Mann B, Wooldridge KG, Abouseada N, et al. Laminin receptor initiates bacterial contact with the blood brain barrier in experimental meningitis models. J Clin Invest. 2009;119:1638-46.

[16] Massari P, Visintin A, Gunawardana J, Halmen KA, King CA, Golenbock DT, et al. Meningococcal porin PorB binds to TLR2 and requires TLR1 for signaling. J Immunol. 2006;176:2373-80.

[17] Bartley SN, Tzeng YL, Heel K, Lee CW, Mowlaboccus S, Seemann T, et al. Attachment and invasion of Neisseria meningitidis to host cells is related to surface hydrophobicity, bacterial cell size and capsule. PloS one. 2013;8:e55798.

[18] Sa ECC, Griffiths NJ, Murillo I, Virji M. Neisseria meningitidis Opc invasin binds to the cytoskeletal protein alpha-actinin. Cell Microbiol. 2009;11:389-405.

[19] Slanina H, Konig A, Hebling S, Hauck CR, Frosch M, Schubert-Unkmeir A. Entry of Neisseria meningitidis into Mammalian Cells Requires the Src Family Protein Tyrosine Kinases. Infection and immunity. 2010;78:1905-14.

[20] Slanina H, Hebling S, Hauck CR, Schubert-Unkmeir A. Cell invasion by Neisseria meningitidis requires a functional interplay between the focal adhesion kinase, Src and cortactin. PloS one. 2012;7:e39613.

[21] Muenzner P, Dehio C, Fujiwara T, Achtman M, Meyer TF, Gray-Owen SD. Carcinoembryonic antigen family receptor specificity of Neisseria meningitidis Opa variants influences adherence to and invasion of proinflammatory cytokine-activated endothelial cells. Infection and immunity. 2000;68:3601-7. 
[22] Virji M, Makepeace K, Ferguson DJ, Watt SM. Carcinoembryonic antigens (CD66) on epithelial cells and neutrophils are receptors for Opa proteins of pathogenic neisseriae. Mol Microbiol. 1996;22:941-50.

[23] Kallstrom H, Liszewski MK, Atkinson JP, Jonsson AB. Membrane cofactor protein (MCP or CD46) is a cellular pilus receptor for pathogenic Neisseria. Molecular Microbiology. 1997;25:639-47.

[24] Kirchner M, Heuer D, Meyer TF. CD46-independent binding of neisserial type IV pili and the major pilus adhesin, PilC, to human epithelial cells. Infection and immunity. 2005;73:3072-82.

[25] Jen FE, Warren MJ, Schulz BL, Power PM, Swords WE, Weiser JN, et al. Dual pili post-translational modifications synergize to mediate meningococcal adherence to platelet activating factor receptor on human airway cells. PLoS Pathog. 2013;9:e1003377.

[26] Quattroni P, Li Y, Lucchesi D, Lucas S, Hood DW, Herrmann M, et al. Galectin-3 binds Neisseria meningitidis and increases interaction with phagocytic cells. Cell Microbiol. 2012;14:1657-75.

[27] Slanina H, Mundlein S, Hebling S, Schubert-Unkmeir A. Role of epidermal growth factor receptor signaling in the interaction of Neisseria meningitidis with endothelial cells. Infection and immunity. 2014;82:1243-55.

[28] Hoffmann I, Eugene E, Nassif X, Couraud PO, Bourdoulous S. Activation of ErbB2 receptor tyrosine kinase supports invasion of endothelial cells by Neisseria meningitidis. J Cell Biol. 2001;155:133-43.

[29] Eswarakumar VP, Lax I, Schlessinger J. Cellular signaling by fibroblast growth factor receptors. Cytokine Growth Factor Rev. 2005;16:139-49.

[30] Guillemot F, Zimmer C. From cradle to grave: the multiple roles of fibroblast growth factors in neural development. Neuron. 2011;71:574-88.

[31] Turner N, Grose R. Fibroblast growth factor signalling: from development to cancer. Nature reviews Cancer. 2010;10:116-29.

[32] Ornitz DM, Itoh N. Fibroblast growth factors. Genome Biol. 2001;2:REVIEWS3005.

[33] Ortega S, Ittmann M, Tsang SH, Ehrlich M, Basilico C. Neuronal defects and delayed wound healing in mice lacking fibroblast growth factor 2. Proceedings of the National Academy of Sciences of the United States of America. 1998;95:5672-7.

[34] Gerwins P, Skoldenberg E, Claesson-Welsh L. Function of fibroblast growth factors and vascular endothelial growth factors and their receptors in angiogenesis. Crit Rev Oncol Hematol. 2000;34:185-94.

[35] Presta M, Dell'Era P, Mitola S, Moroni E, Ronca R, Rusnati M. Fibroblast growth factor/fibroblast growth factor receptor system in angiogenesis. Cytokine Growth Factor Rev. 2005;16:159-78.

[36] Groth C, Lardelli M. The structure and function of vertebrate fibroblast growth factor receptor 1 . Int J Dev Biol. 2002;46:393-400.

[37] Miki T, Bottaro DP, Fleming TP, Smith CL, Burgess WH, Chan AM, et al. Determination of ligand-binding specificity by alternative splicing: two distinct growth factor receptors encoded by a single gene. Proceedings of the National Academy of Sciences of the United States of America. 1992;89:246-50.

[38] Latko M, Czyrek A, Porebska N, Kucinska M, Otlewski J, Zakrzewska M, et al. Cross-Talk between Fibroblast Growth Factor Receptors and Other Cell Surface Proteins. Cells. 2019;8.

[39] Reiland J, Rapraeger AC. Heparan sulfate proteoglycan and FGF receptor target basic FGF to different intracellular destinations. J Cell Sci. 1993;105 ( Pt 4):1085-93.

[40] Ornitz DM, Yayon A, Flanagan JG, Svahn CM, Levi E, Leder P. Heparin is required for cell-free binding of basic fibroblast growth factor to a soluble receptor and for mitogenesis in whole cells. Molecular and cellular biology. 1992;12:240-7.

[41] Cavallaro U, Christofori G. Cell adhesion and signalling by cadherins and Ig-CAMs in cancer. Nature reviews Cancer. 2004;4:118-32.

[42] Francavilla C, Cattaneo P, Berezin V, Bock E, Ami D, de Marco A, et al. The binding of NCAM to FGFR1 induces a specific cellular response mediated by receptor trafficking. J Cell Biol. 2009;187:1101-16.

[43] Zhang X, Ibrahimi OA, Olsen SK, Umemori H, Mohammadi M, Ornitz DM. Receptor specificity of the fibroblast growth factor family. The complete mammalian FGF family. J Biol Chem. 2006;281:15694-700.

[44] Lundin L, Ronnstrand L, Cross M, Hellberg C, Lindahl U, Claesson-Welsh L. Differential tyrosine phosphorylation of fibroblast growth factor (FGF) receptor-1 and receptor proximal signal transduction in response to FGF-2 and heparin. Exp Cell Res. 2003;287:190-8. 
[45] Mohammadi M, Dikic I, Sorokin A, Burgess WH, Jaye $M$, Schlessinger J. Identification of six novel autophosphorylation sites on fibroblast growth factor receptor 1 and elucidation of their importance in receptor activation and signal transduction. Molecular and cellular biology. 1996;16:977-89.

[46] Mohammadi M, Dionne CA, Li W, Li N, Spivak T, Honegger AM, et al. Point mutation in FGF receptor eliminates phosphatidylinositol hydrolysis without affecting mitogenesis. Nature. 1992;358:681-4.

[47] Murakami M, Nguyen LT, Zhuang ZW, Moodie KL, Carmeliet P, Stan RV, et al. The FGF system has a key role in regulating vascular integrity. J Clin Invest. 2008;118:3355-66.

[48] Kanda S, Landgren E, Ljungstrom M, Claesson-Welsh L. Fibroblast growth factor receptor 1-induced differentiation of endothelial cell line established from tsA58 large $T$ transgenic mice. Cell growth \& differentiation : the molecular biology journal of the American Association for Cancer Research. 1996;7:38395.

[49] Tettelin H, Saunders NJ, Heidelberg J, Jeffries AC, Nelson KE, Eisen JA, et al. Complete genome sequence of Neisseria meningitidis serogroup B strain MC58. Science. 2000;287:1809-15.

[50] Fleischmann RD, Adams MD, White O, Clayton RA, Kirkness EF, Kerlavage AR, et al. Whole-genome random sequencing and assembly of Haemophilus influenzae Rd. Science. 1995;269:496-512.

[51] Fernebro J, Andersson I, Sublett J, Morfeldt E, Novak R, Tuomanen E, et al. Capsular expression in Streptococcus pneumoniae negatively affects spontaneous and antibiotic-induced lysis and contributes to antibiotic tolerance. J Infect Dis. 2004;189:328-38.

[52] Oldfield NJ, Bland SJ, Taraktsoglou M, Dos Ramos FJ, Robinson K, Wooldridge KG, et al. T-cell stimulating protein A (TspA) of Neisseria meningitidis is required for optimal adhesion to human cells. Cell Microbiol. 2007;9:463-78.

[53] Wheldon LM, Khodabukus N, Patey SJ, Smith TG, Heath JK, Hajihosseini MK. Identification and characterization of an inhibitory fibroblast growth factor receptor 2 (FGFR2) molecule, up-regulated in an Apert Syndrome mouse model. Biochem J. 2011;436:71-81.

[54] Burgar HR, Burns HD, Elsden JL, Lalioti MD, Heath JK. Association of the signaling adaptor FRS2 with fibroblast growth factor receptor 1 (Fgfr1) is mediated by alternative splicing of the juxtamembrane domain. J Biol Chem. 2002;277:4018-23.

[55] Mizushima S, Nagata S. pEF-BOS, a powerful mammalian expression vector. Nucleic acids research. 1990;18:5322.

[56] Alqahtani F, Mahdavi J, Wheldon LM, Vassey M, Pirinccioglu N, Royer PJ, et al. Deciphering the complex three-way interaction between the non-integrin laminin receptor, galectin-3 and Neisseria meningitidis. Open Biol. 2014;4.

[57] Virion Z, Doly S, Saha K, Lambert M, Guillonneau F, Bied C, et al. Sialic acid mediated mechanical activation of beta2 adrenergic receptors by bacterial pili. Nat Commun. 2019;10:4752.

[58] Coureuil M, Lecuyer H, Scott MG, Boularan C, Enslen H, Soyer M, et al. Meningococcus Hijacks a beta2adrenoceptor/beta-Arrestin pathway to cross brain microvasculature endothelium. Cell. 2010;143:1149-60. [59] Coureuil M, Mikaty G, Miller F, Lecuyer H, Bernard C, Bourdoulous S, et al. Meningococcal type IV pili recruit the polarity complex to cross the brain endothelium. Science. 2009;325:83-7.

[60] Unkmeir A, Latsch K, Dietrich G, Wintermeyer E, Schinke B, Schwender S, et al. Fibronectin mediates Opc-dependent internalization of Neisseria meningitidis in human brain microvascular endothelial cells. Mol Microbiol. 2002;46:933-46.

[61] Schubert-Unkmeir A, Konrad C, Slanina H, Czapek F, Hebling S, Frosch M. Neisseria meningitidis induces brain microvascular endothelial cell detachment from the matrix and cleavage of occludin: a role for MMP8. PLoS Pathog. 2010;6:e1000874.

[62] van Hinsbergh VW, Rabelink TJ. FGFR1 and the bloodline of the vasculature. Arteriosclerosis, thrombosis, and vascular biology. 2005;25:883-6.

[63] Elfenbein A, Lanahan A, Zhou TX, Yamasaki A, Tkachenko E, Matsuda M, et al. Syndecan 4 regulates FGFR1 signaling in endothelial cells by directing macropinocytosis. Sci Signal. 2012;5:ra36.

[64] Estes NR, 2nd, Thottassery JV, Kern FG. siRNA mediated knockdown of fibroblast growth factor receptors 1 or 3 inhibits FGF-induced anchorage-independent clonogenicity but does not affect MAPK activation. Oncology reports. 2006;15:1407-16. 
[65] Miller F, Lecuyer H, Join-Lambert O, Bourdoulous S, Marullo S, Nassif X, et al. Neisseria meningitidis colonization of the brain endothelium and cerebrospinal fluid invasion. Cell Microbiol. 2012.

[66] Liu J, Huang C, Zhan X. Src is required for cell migration and shape changes induced by fibroblast growth factor 1. Oncogene. 1999;18:6700-6.

[67] Zhan X, Plourde C, Hu X, Friesel R, Maciag T. Association of fibroblast growth factor receptor-1 with cSrc correlates with association between c-Src and cortactin. J Biol Chem. 1994;269:20221-4.

[68] Landgren E, Blume-Jensen P, Courtneidge SA, Claesson-Welsh L. Fibroblast growth factor receptor-1 regulation of Src family kinases. Oncogene. 1995;10:2027-35.

[69] Kim JH, Jiang S, Elwell CA, Engel JN. Chlamydia trachomatis co-opts the FGF2 signaling pathway to enhance infection. PLoS Pathog. 2011;7:e1002285.

[70] Sahni A, Patel J, Narra HP, Schroeder CLC, Walker DH, Sahni SK. Fibroblast growth factor receptor-1 mediates internalization of pathogenic spotted fever rickettsiae into host endothelium. PloS one. 2017;12:e0183181.

[71] Klughammer J, Dittrich M, Blom J, Mitesser V, Vogel U, Frosch M, et al. Comparative Genome Sequencing Reveals Within-Host Genetic Changes in Neisseria meningitidis during Invasive Disease. PloS one. 2017;12:e0169892. 

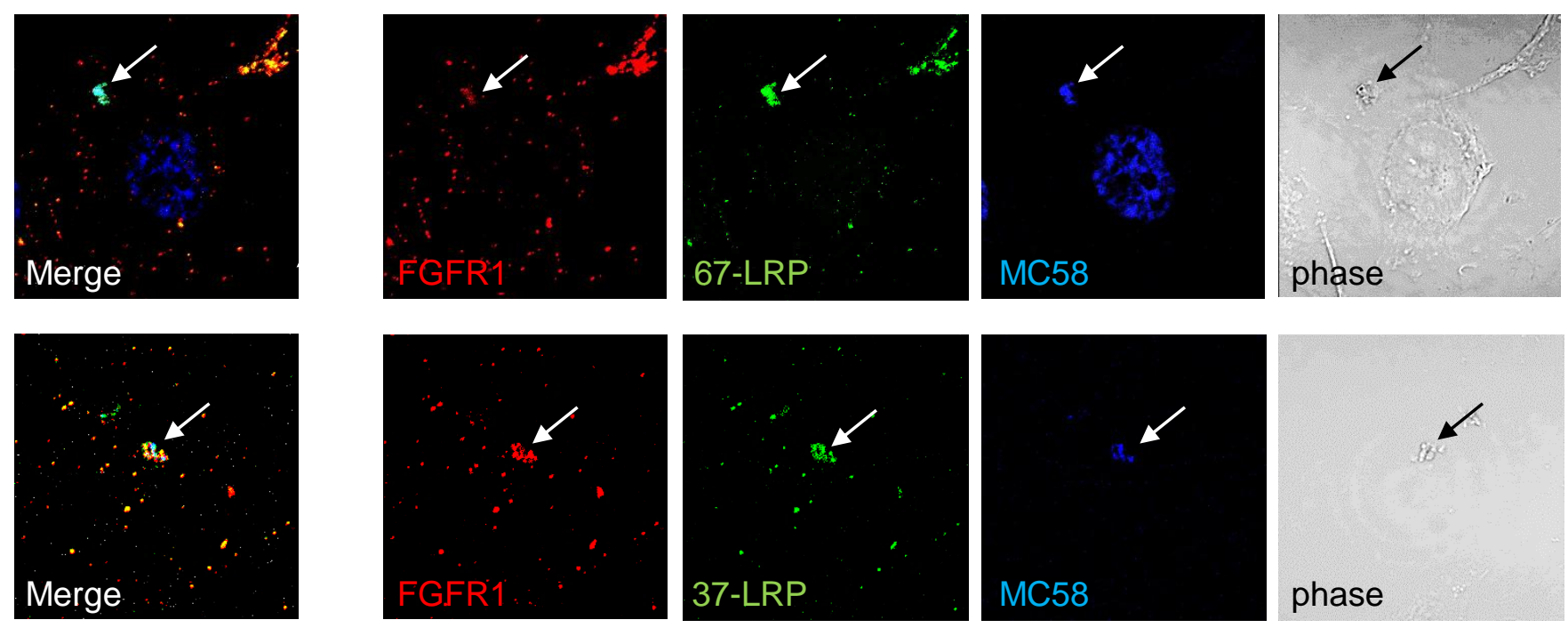

B
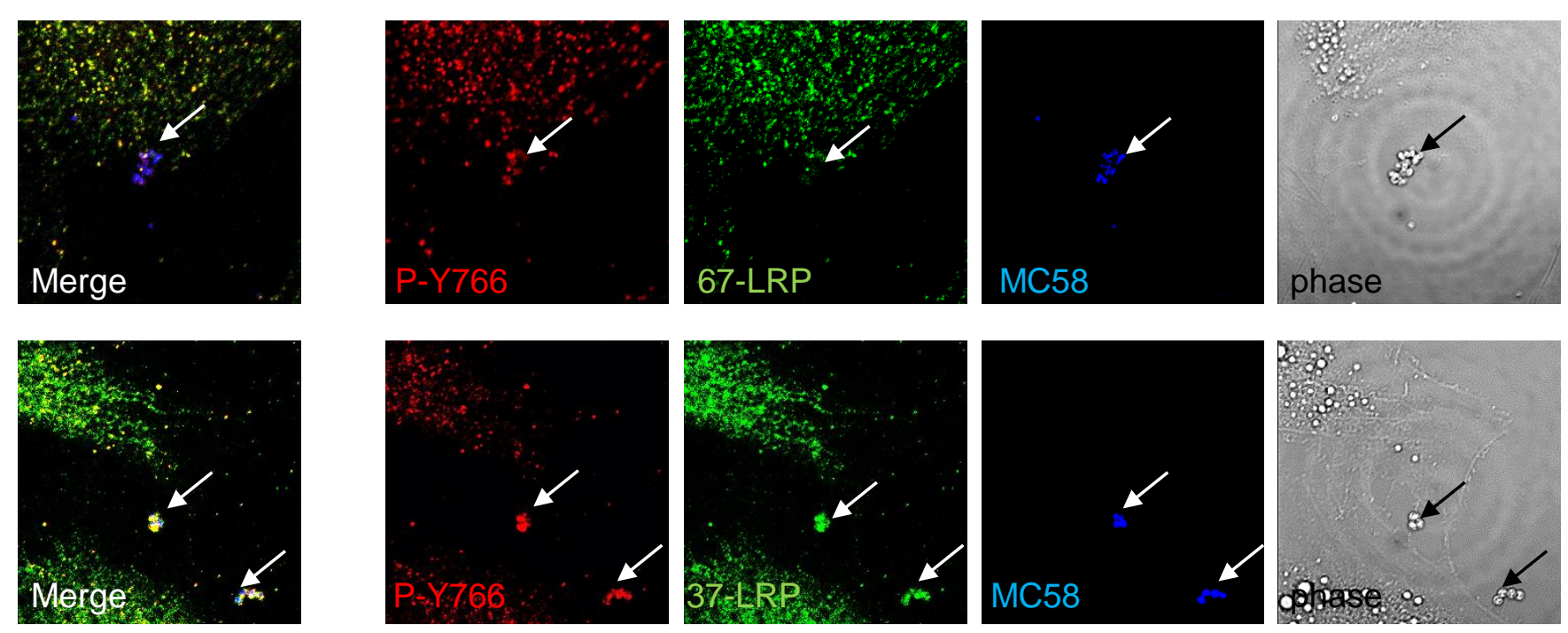

C

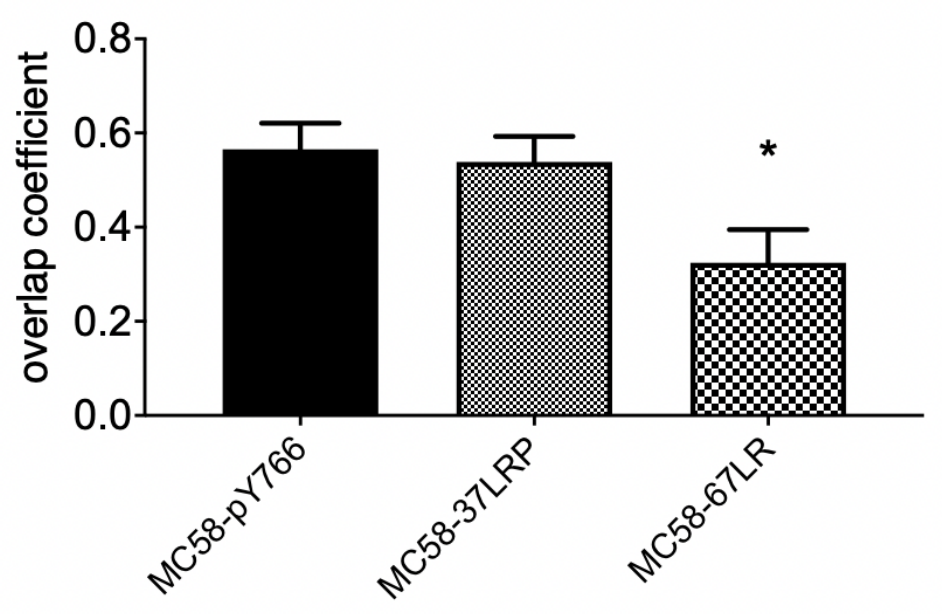


A
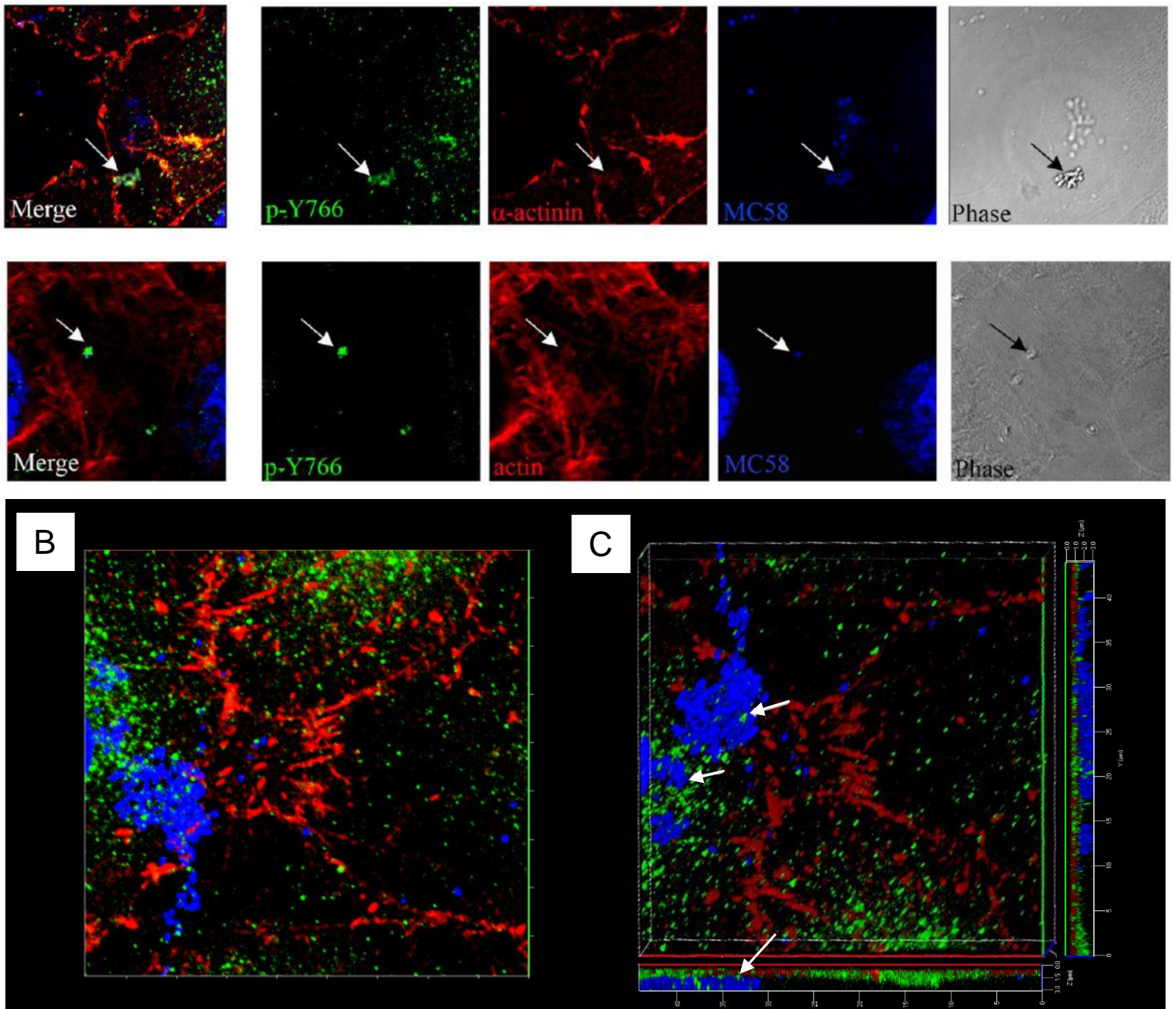

D

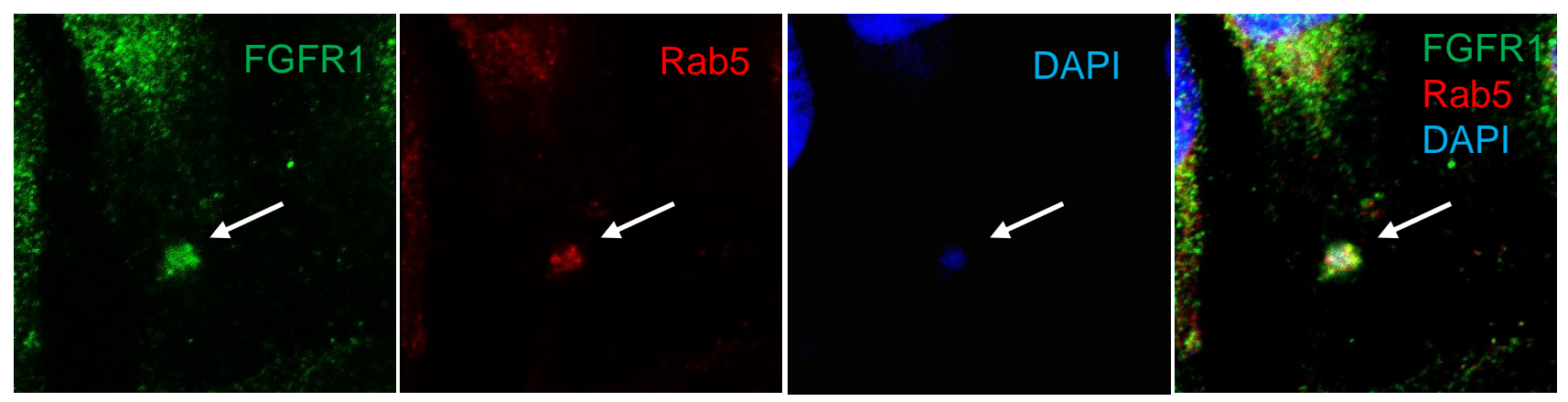


A

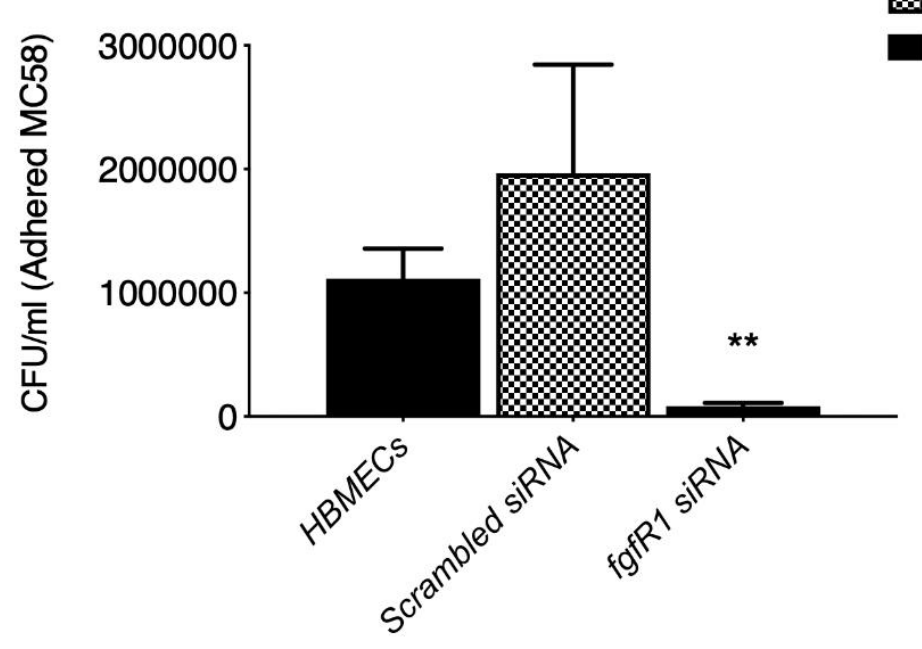

B

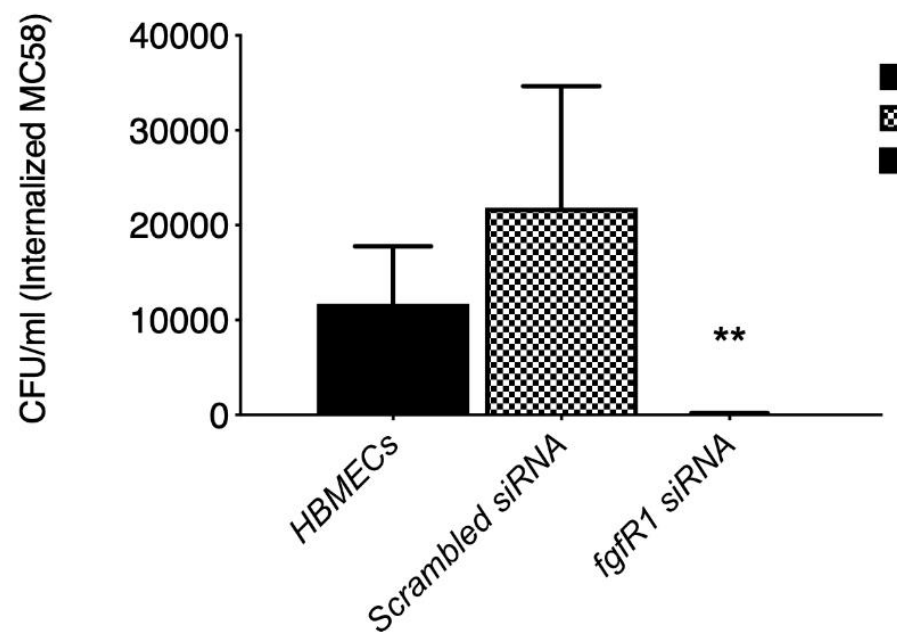

HBMECs

B. Scrambled siRNA

fgfR1 siRNA
HBMECs

Scrambled siRNA

fgfR1 siRNA

Figure 3 
A

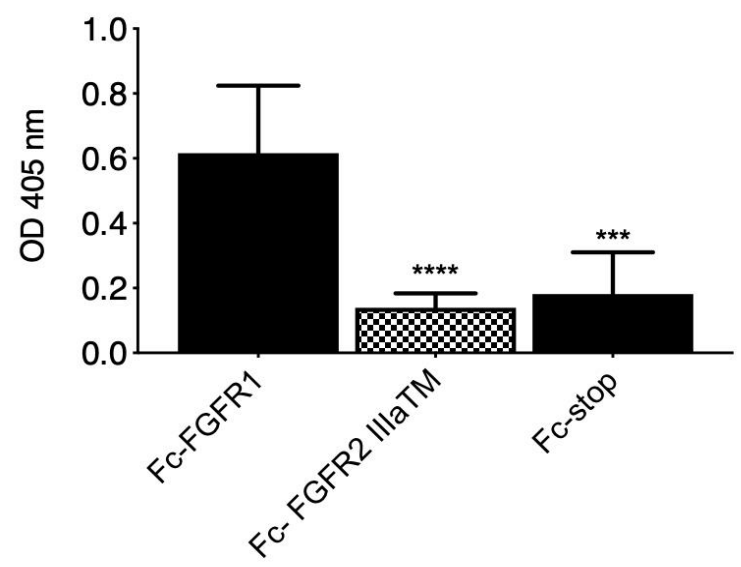

FGFR1

E Fc- FGFR2 IIlaTM

B

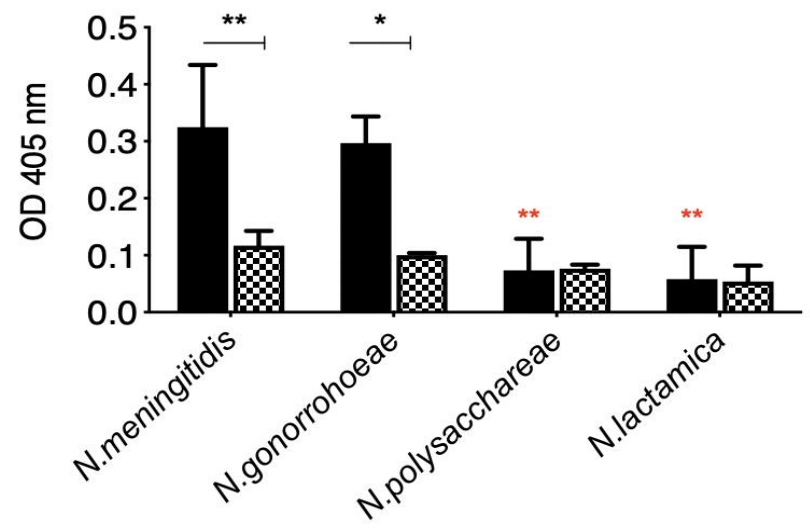

C

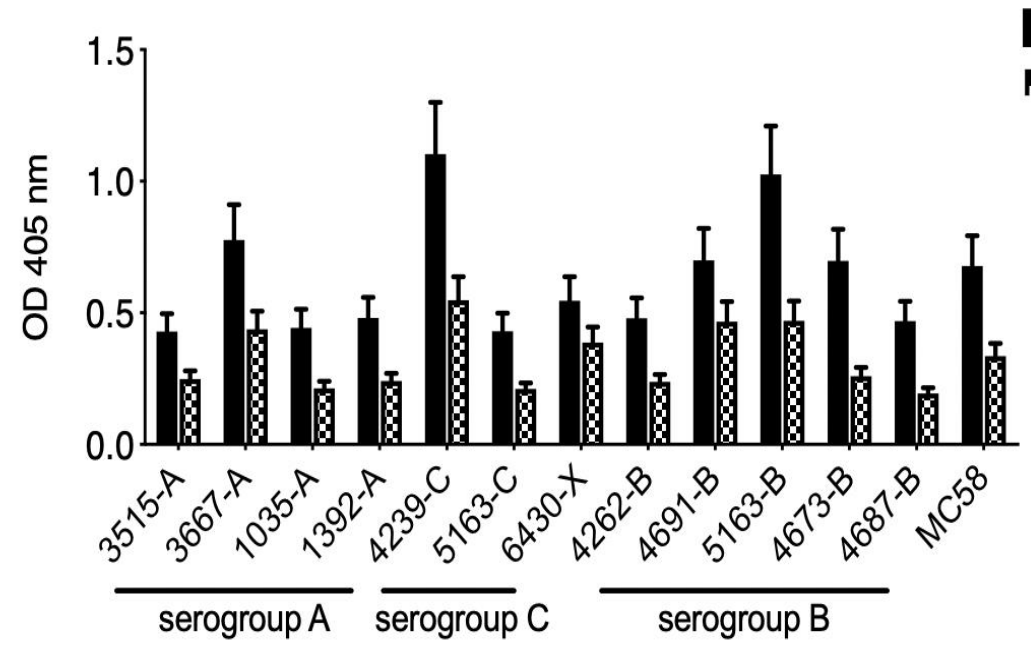

D

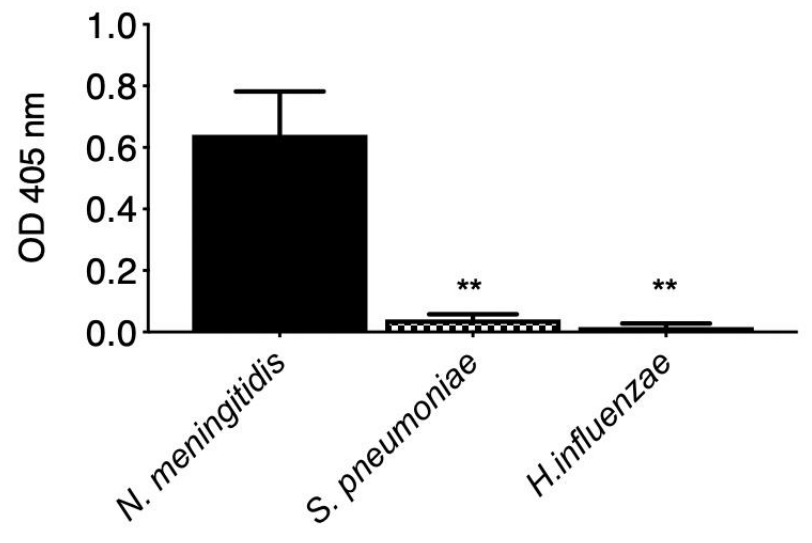


Additional images for review 

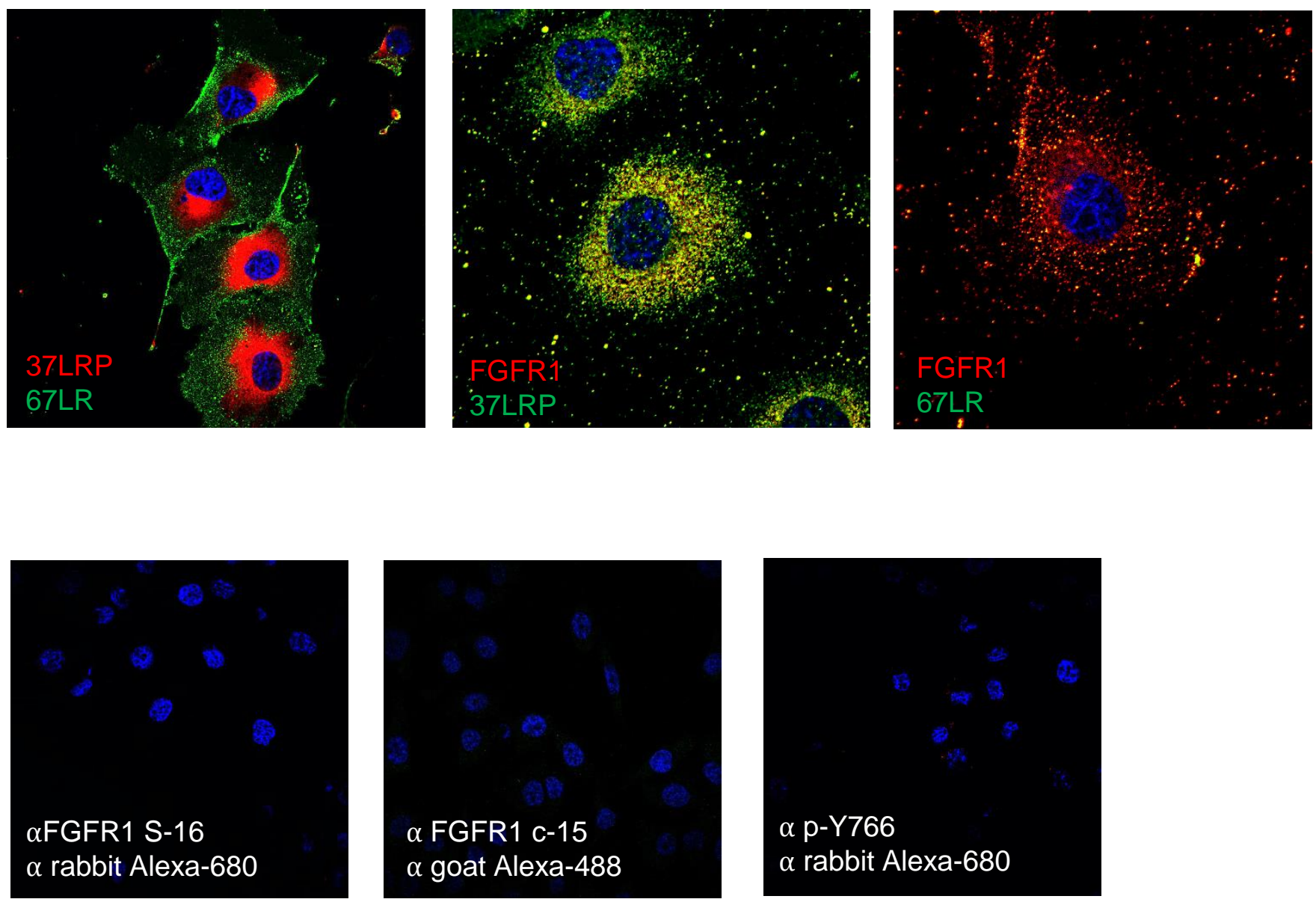

Figure R1. Images of uninfected HBMECs, and the localization patterns of 37LRP and 67LR in regards to FGFR1. We found no cross reactivity of secondary antibodies against 37LRP and 67LR with FGFR1 primary antibodies (S-16 or C-15). 
HBMEC cytoplasm

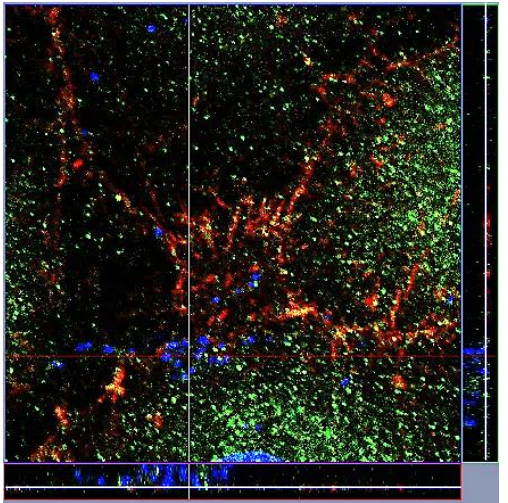

HBMEC membrane

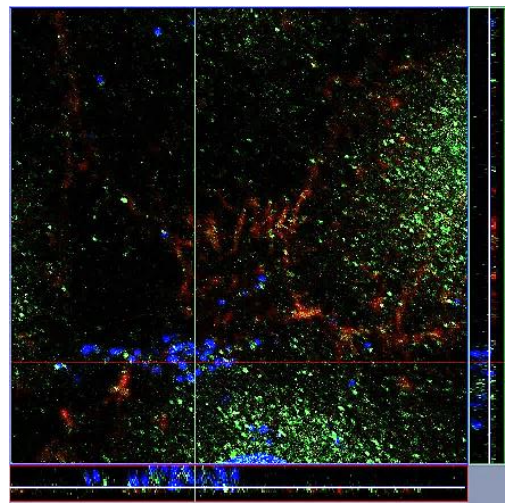

HBMEC apical surface

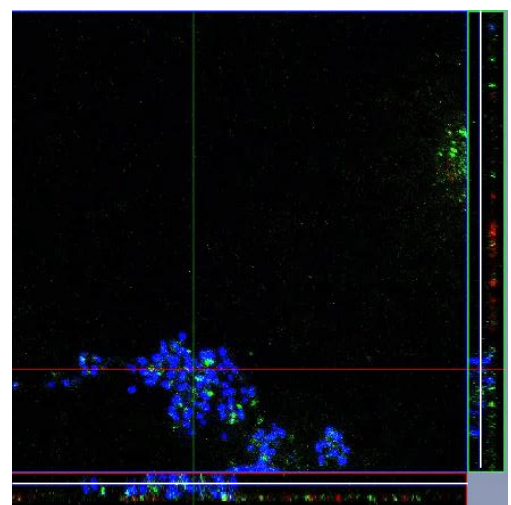

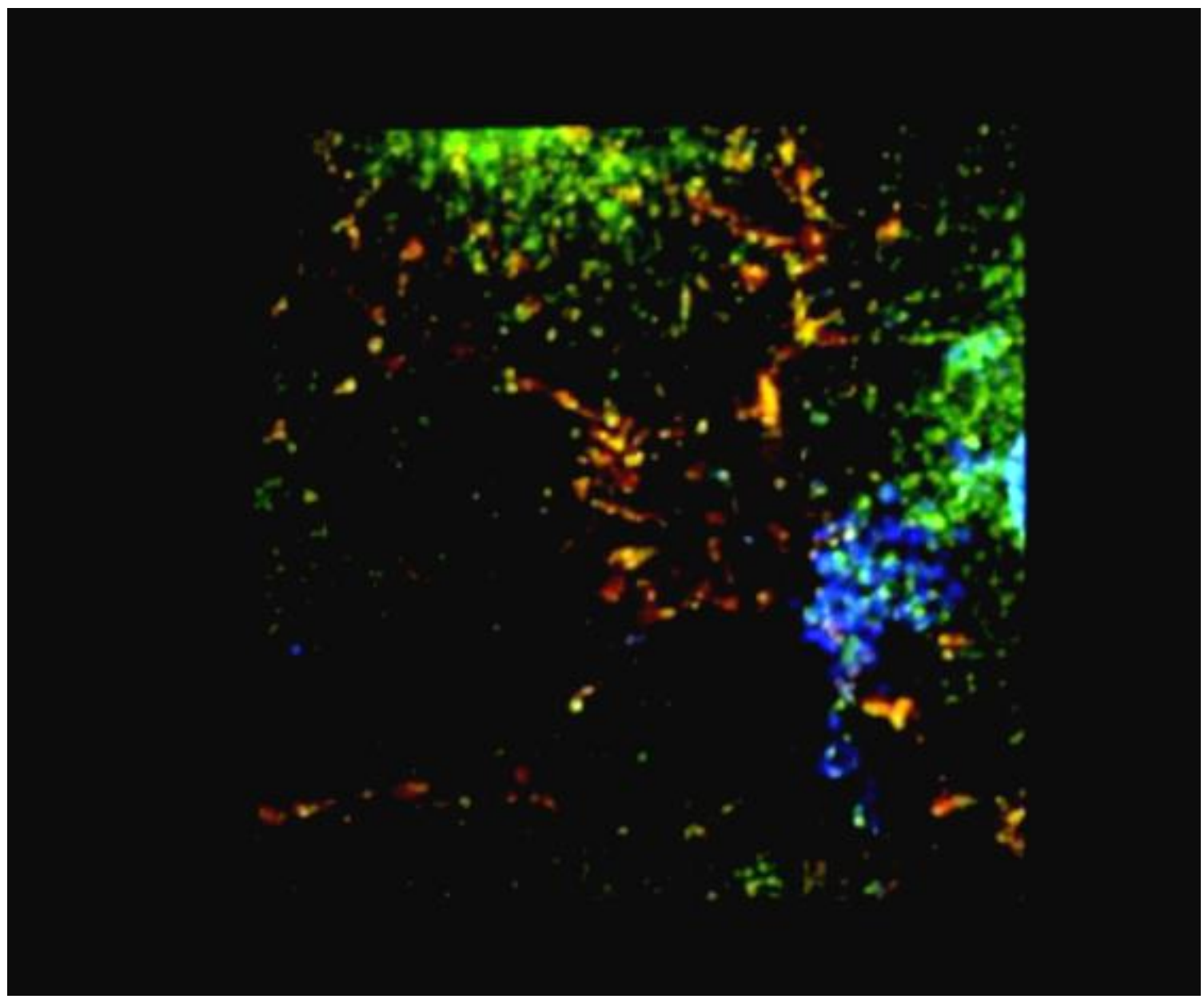

Figure R2. MC58 cells recruit activated FGFR1 (p-Y766 in green) on apical surface of the cells and internalised bacterial cell are co-localized with $\alpha$-actinin in cytoplasm. 
Conflict of Interest

\title{
Competing interests
}

\begin{abstract}
The authors declare that they have no competing interests.
\end{abstract}




\section{Author Statement}

Sheyda Azimi undertook the majority of the practical work under the day-to-day guidance of Lee Wheldon. The programme of work was directed by Karl Wooldridge, Neil Oldfield and Lee Wheldon. The paper was written by Sheyda Azimi, Lee Wheldon and Karl Wooldridge. All authors regularly reviewed the work and commented on draft manuscripts. 